\title{
1,5-Substitution Reactions
}

\section{Iron-Promoted 1,5-Substitution $\left(\mathrm{S}_{\mathrm{N}} 2^{\prime \prime}\right)$ Reactions of Enyne Acetates and Oxiranes with Grignard Reagents}

\author{
Doğan Taç, ${ }^{[a]}$ İsmet Arınç Aytaç, ${ }^{[a]}$ Ali Osman Karatavuk, ${ }^{[b]}$ Melih Kuş, ${ }^{[a]}$ Fırat Ziyanak, ${ }^{[a]}$ and \\ Levent Artok*[a]
}

\begin{abstract}
Acetate derivatives of 2-en-4-yne alcohols 1 and enyne oxiranes 4 regioselectively underwent 1,5-substitution $\left(\mathrm{S}_{\mathrm{N}} 2^{\prime \prime}\right)$ reactions with Grignard reagents in the presence of an iron compound to provide vinylallenes exclusively with the $(E)$-configuration. An alkali salt was needed to avoid the
\end{abstract}

hydride-promoted reductive 1,5-substitution pathway for 1 , whereas no such additive was needed for the effective conversion of $\mathbf{4}$ into the desired alkylated or arylated vinylallene structure.

\section{Introduction}

Vinylallenes are exceptionally reactive compounds in various cycloaddition, cyclization, and isomerization reactions. ${ }^{[1]}$ In particular, their unique reactivity and selectivity in [4+2] reactions are beneficial in the synthesis of several naturally occurring reagents. $^{[2]}$

It has previously been established that the 1,5-substitution $\left(\mathrm{S}_{\mathrm{N}} 2^{\prime \prime}\right)$ reaction of conjugated enynes that contain a leaving group at the allylic position with carbon nucleophiles affords vinylallene structures. This strategy was first introduced by Gore and Dulcere, ${ }^{[3]}$ who found that the reaction of 1-chloro-2en-4-ynes with either methylmagnesium iodide or trimethylsilylmagnesium chloride (or trimethylsilyllithium) in the absence of a metal catalyst produced an $E / Z$ mixture of vinylallenes (Scheme 1). The method, however, was not general, as other Grignard reagents failed to form the desired vinylallenes.

Krause et al. developed a more general method, in which they found (E)-2-en-4-yne acetates to regioselectively undergo $\mathrm{S}_{\mathrm{N}} 2$-'-type alkylation reactions with various lithium cuprates to exclusively afford vinylallenes (Scheme 2). ${ }^{[4]}$ However, this approach usually provided the vinylallenes as mixtures of $E$ and $Z$ isomers, even though a chirality transfer could be realized from centrally chiral enyne acetate substrates to axially chiral

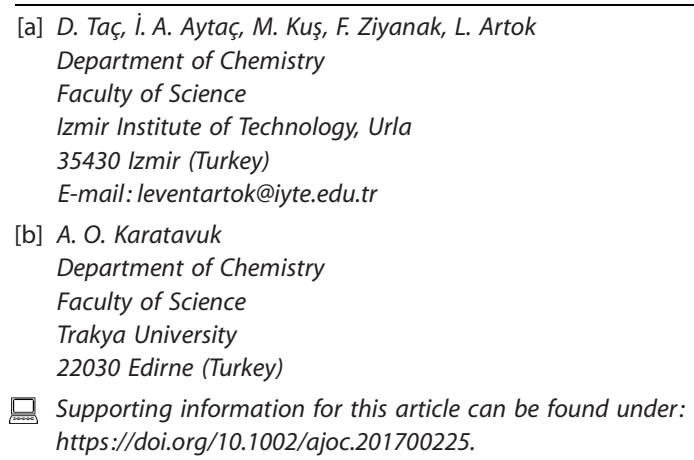

Scheme 1. 1,5-Substitution reaction of 1-(1-chloroethyl)-2-ethynylcyclohex-1ene with Grignard reagents (HMPA = hexamethylphosphoramide).

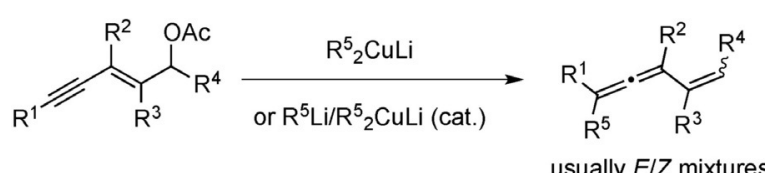

Scheme 2. 1,5-Substitution of 2-en-4-yne acetates with lithium organocuprates.

products in the presence of $\mathrm{Bu}_{3} \mathrm{P}$ as a ligand. ${ }^{[4 \mathrm{~b}]}$ This group also applied their method to two enyne oxirane structures that have an E-configured alkenyl moiety. This strategy, however, had a limited scope for both enyne substrates and their reacting partners. ${ }^{[4 b]}$

Metal-catalyzed substitution and coupling reactions of carbonates and acetates of enynols as well as enyne oxiranes are also of interest to us. We recently revealed that these enyne reagents could be converted by palladium or rhodium catalysis into vinylallenes that are substituted with ester, aryl, or alkenyl functionalities. ${ }^{[5]}$ On the basis of our experience regarding the synthesis and chemistry of these compound types and by considering earlier reports of methods for iron-catalyzed $\mathrm{S}_{\mathrm{N}} 2^{\prime}$-type reactions of propargylic epoxides ${ }^{[6]}$ and 1,6-addition reactions of enyne esters ${ }^{[7]}$ with Grignard reagents to give allene products, we have developed $\mathrm{S}_{\mathrm{N}} 2^{\prime \prime}$ reactions that use convenient 
Grignard reagents as nucleophiles and virtually nontoxic iron compounds as catalysts. ${ }^{[8]}$

\section{Results and Discussion}

\section{Iron-Promoted Reaction of 2-En-4-yne Acetates and Grignard Reagents}

The slow addition (20-30 min) of $\mathrm{BuMgCl}$ in $\mathrm{Et}_{2} \mathrm{O}$ to an equimolar mixture of (Z)-enyne acetate $\mathbf{1} \mathrm{a}$ and an iron compound in tetrahydrofuran (THF) at $-50^{\circ} \mathrm{C}$ followed by stirring for a period of time exclusively resulted in $(E)$-vinylallene 2 aa in good yield (Table 1). Although $\mathrm{FeCl}_{2}$ provided better product

Table 1. Optimization of reaction conditions for iron-promoted 1,5-substitution of enyne acetate 1 a with $\mathrm{BuMgCl}^{[\mathrm{a}]}$

\begin{tabular}{|c|c|c|c|c|c|}
\hline Du & $\bigwedge_{1 \mathrm{a}}^{\mathrm{Me}} \mathrm{OAc}$ & $\begin{array}{l}\text { uMgCl (3 equiv) } \\
{[\mathrm{Fe}]} \\
\text { Additive, THF }\end{array}$ & $\underset{\mathrm{Bu}}{\mathrm{Bu}}=\cdot=$ & ${ }_{\mathrm{Bu}}^{+}$ & $\stackrel{\mathrm{Bu}}{=}=\underbrace{\mathrm{Me}}_{3 \mathrm{a}}$ \\
\hline Entry & Configuration & [Fe] [mol\%] & Additive $^{[b]}$ & $t[\mathrm{~h}]^{[\mathrm{c}]}$ & $\%$ Yield $^{[\mathrm{d}]} \mathbf{2}$ aa \\
\hline 1 & $Z$ & $\mathrm{FeCl}_{2}(100)$ & - & 4.0 & 87 \\
\hline 2 & $Z$ & $\mathrm{Fe}(\mathrm{acac})_{3}(100)$ & - & 2.0 & 74 \\
\hline 3 & $Z$ & $\mathrm{FeCl}_{2}(20)$ & - & 4.0 & $70(11)^{[\mathrm{e}]}$ \\
\hline 4 & Z & $\mathrm{FeCl}_{2}(20)$ & $\mathrm{LiCl}$ & 1.5 & 87 \\
\hline 5 & $Z$ & $\mathrm{FeCl}_{2}(20)$ & $\mathrm{LiBr}$ & 1.5 & 80 \\
\hline 6 & Z & $\mathrm{FeCl}_{2}(20)$ & KI & 1.5 & 82 \\
\hline 7 & $Z$ & $\mathrm{FeCl}_{2}(20)$ & Nal & 1.5 & 81 \\
\hline 8 & $E$ & $\mathrm{FeCl}_{2}(20)$ & $\mathrm{KI}$ & 4.0 & 88 \\
\hline $9^{[f]}$ & $E$ & $\mathrm{FeCl}_{2}(20)$ & $\mathrm{KI}$ & 1.5 & $90,86^{[\mathrm{g}]}$ \\
\hline
\end{tabular}

[a] Reagents and conditions: 1 a $(0.1 \mathrm{mmol}), \mathrm{BuMgCl}$ (3 equiv), and $\mathrm{FeCl}_{2}$ (20 mol\%) in THF ( $3 \mathrm{~mL}$ ) at $-50{ }^{\circ} \mathrm{C}$. [b] Additive (2 equiv) was used in those reactions above that report the use of a salt. [c] Includes the addition period of $\mathrm{BuMgCl}$. [d] Determined by ${ }^{1} \mathrm{H}$ NMR analysis using $p$-anisaldehyde as the internal standard. [e] Percent yield of $\mathbf{3} \mathbf{a}$. [f] Performed at $-40{ }^{\circ} \mathrm{C}$. [g] Yield of isolated product is provided.

selectivity than $\mathrm{Fe}(\mathrm{acac})_{3}$ (acac = acetylacetonate, Table 1, entries 1 and 2), we found that loading $\mathrm{FeCl}_{2}$ in smaller amounts, such as $20 \mathrm{~mol} \%$, gave a decreased yield of 2 aa because of the prominent formation of the inseparable reduction by-product (E)-7-methyltrideca-5,6,8-triene ( 3 a, Table 1, entry 3). The formation of 3 a could be eliminated, and thus a higher yield of $\mathbf{2}$ aa could be attained in a shorter period of time by adding alkali salts to the reaction medium. Although the maximum yield of vinylallene $\mathbf{2}$ aa was formed in the presence of $\mathrm{LiCl}$, we were not eager to use $\mathrm{LiCl}$ or the other lithium salt in this study, $\mathrm{LiBr}$, as additives in other reactions. In the presence of both of these salts, the formation of $\mathbf{2}$ aa was invariably accompanied by an inseparable mixture of isomers (Table 1, entries 4 and 5).

The pure products were recovered in virtually comparable yields from the reactions that were performed in the presence of 2 equiv of KI (Table 1, entry 6 ) and Nal (Table 1, entry 7). The (E)-configured substrate 1 a performed better in the reaction with $\mathrm{KI}$ as an additive and provided 2 aa in $88 \%$ NMR yield, albeit over a longer reaction time (Table 1, entry 8 ). Nevertheless, increasing the reaction temperature from -50 to $-40^{\circ} \mathrm{C}$ accelerated the rate, with an isolated yield of $86 \%$ (Table 1, entry 9).

The positive effect from the salt additive is not clear at this time, but it has been shown that the addition of salts is particularly useful to hinder side reactions from processes that involve Grignard reagents. For example, a $\beta-\mathrm{H}$ transfer is likely to be responsible for the formation of reduction product $3 .{ }^{[8,9]}$ In addition, salts are also used to promote the cleavage of esters. $^{[10]}$

After establishing the optimum reaction conditions (i.e., Table 1, entry 9), we explored the suitability of a number of Grignard reagents in their reactions with $(E)-\mathbf{1} \mathbf{a}$. This method is apparently sensitive to the size of the Grignard reagents, as the method is more applicable towards Grignard reagents that contain primary alkyl groups (Table 2 , entries $1-3$ ). ${ }^{[11]}$ The reac-

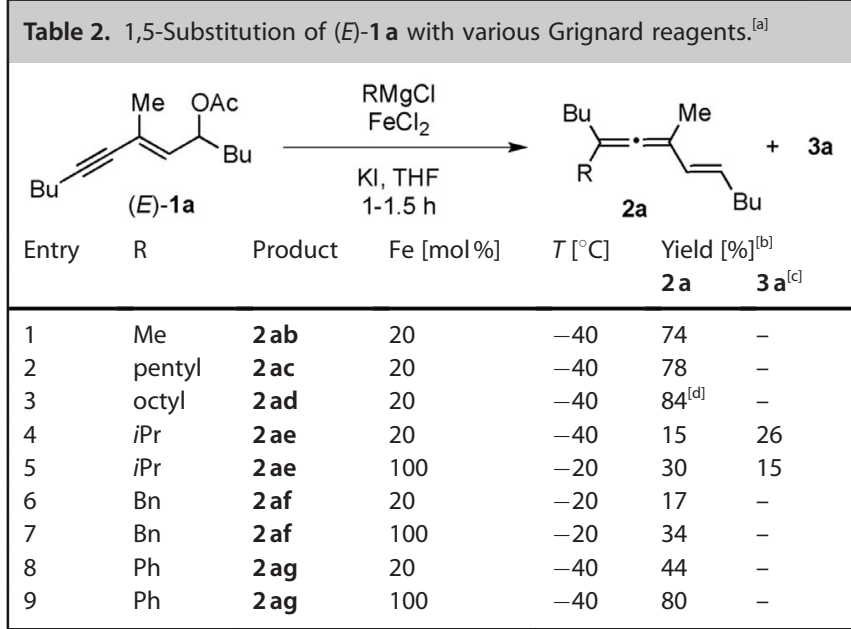

[a] Reagents and conditions: $(E)-1$ a $(0.1 \mathrm{mmol}), \mathrm{RMgCl}$ (3 equiv), and $\mathrm{KI}$ ( 2 equiv) in THF $(3 \mathrm{~mL})$. [b] Yields of isolated products are provided. [c] Yield determined by ${ }^{1} \mathrm{H}$ NMR analysis. [d] The sample is contaminated with $4 \mathrm{~mol} \%$ of hexadecane with respect to the $1 \mathrm{a}$ amount. The yield represents the amount of $\mathbf{2}$ ad only.

tion with $i \mathrm{PrMgCl}$ proceeded to give the product with poor selectivity and, in turn, resulted in the formation of mixture of alkylated vinylallene $\mathbf{2}$ ae as well as by-product $\mathbf{3}$ a (Table 2, entries 4 and 5). In contrast, only a modest yield of benzylated vinylallene $\mathbf{2}$ af was recovered from the reaction performed with $\mathrm{BnMgCl}$, probably because of electronic reasons. Under more driving conditions, such as a reaction temperature of $-20^{\circ} \mathrm{C}$ and in the presence of an equivalent amount of $\mathrm{FeCl}_{2}$, complete conversion of 1 a could not be achieved (Table 2, entries 6 and 7). Although a high catalyst loading is required, an arylative 1,5-substitution was possible (Table 2, entries 8 and 9), as the reaction of $(E)-1 \mathrm{a}$ and $\mathrm{PhMgCl}$ in the presence an equivalent amount of iron catalyst furnished vinylallene $\mathbf{2}$ ag in good yield.

The 1,5-substitution reactions were also carried out with a series of different $(E)$-enyne acetates. Apparently, the alkynyl moiety must be substituted for the method to be successful. Enyne acetate $(E)-\mathbf{1} \mathbf{b}$ that has a terminal alkynyl group $\left(\mathrm{R}^{1}=\mathrm{H}\right)$ led to a complex mixture when treated with $\mathrm{BuMgCl}$ (Table 3, 
Table 3. 1,5-Substitution reaction of $(E)$-enyne acetates with BuMgCl. ${ }^{[a]}$
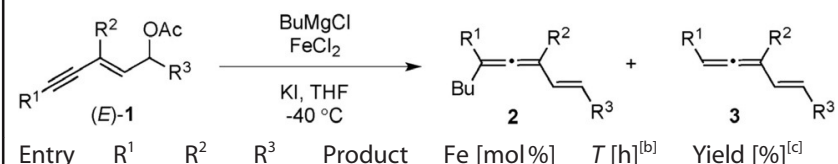

Entry $\quad \mathrm{R}^{1} \quad \mathrm{R}^{2} \quad \mathrm{R}^{3} \quad$ Product $\mathrm{Fe}[\mathrm{mol} \%] \quad T[\mathrm{~h}]^{[\mathrm{b}]} \quad$ Yield [\% ${ }^{[\mathrm{cc}]}$

\begin{tabular}{|c|c|c|c|c|c|c|c|c|}
\hline 1 & $\mathrm{H}$ & $\mathrm{Me}$ & $\mathrm{Bu}$ & $2 \mathrm{ba}$ & 20 & 4.5 & trace & - \\
\hline $2^{[\mathrm{e}]}$ & $C y$ & $\mathrm{Me}$ & $\mathrm{Bu}$ & $2 \mathrm{ca}$ & 20 & 2.5 & 35 & 7 \\
\hline 3 & Cy & $\mathrm{Me}$ & $\mathrm{Bu}$ & $2 \mathrm{ca}$ & 100 & 2.5 & 67 & 6 \\
\hline $4^{[\mathrm{e}]}$ & $t \mathrm{Bu}$ & $\mathrm{Me}$ & $\mathrm{Bu}$ & $2 \mathrm{da}$ & 100 & 1.5 & trace & - \\
\hline 5 & $\mathrm{Ph}$ & $\mathrm{Me}$ & $\mathrm{Bu}$ & 2 ea & 20 & 0.45 & 91 & - \\
\hline 6 & $\mathrm{Bu}$ & $\mathrm{H}$ & $\mathrm{Bu}$ & $2 \mathrm{fa}$ & 20 & 2.5 & $56^{[d]}$ & - \\
\hline 7 & $\mathrm{Bu}$ & $\mathrm{Bu}$ & $\mathrm{Bu}$ & $2 \mathrm{ga}$ & 20 & 1.5 & 80 & - \\
\hline $8^{[\mathrm{e}]}$ & $\mathrm{Bu}$ & Cy & $\mathrm{Bu}$ & 2 ha & 100 & 3.5 & trace & - \\
\hline 9 & $\mathrm{Bu}$ & $\mathrm{Me}$ & $\mathrm{H}$ & 2 ia & 20 & 2.5 & 89 & - \\
\hline 10 & $\mathrm{Bu}$ & $\mathrm{Me}$ & $\mathrm{Me}$ & $2 \mathrm{ja}$ & 20 & 1.5 & 91 & - \\
\hline 11 & $\mathrm{Bu}$ & $\mathrm{Me}$ & $i \mathrm{Pr}$ & 2 ka & 20 & 2.5 & 78 & - \\
\hline 12 & $\mathrm{Bu}$ & $\mathrm{Me}$ & $\mathrm{Ph}$ & 2 la & 20 & 1 & $75^{[\mathrm{d}]}$ & - \\
\hline
\end{tabular}

[a] Reagents and conditions: $(E)-1(0.1 \mathrm{mmol}), \mathrm{BuMgCl}$ (3 equiv), and $\mathrm{KI}$ ( 2 equiv) in THF $(3 \mathrm{~mL})$. [b] Includes the addition period of the Grignard reagent. [c] Yields of isolated products are provided. [d] Determined by ${ }^{1} \mathrm{H}$ NMR analysis. [e] The conversion was incomplete.

entry 1). In contrast, the reactivity of the enyne is strongly influenced by the size of $R^{1}$ and the type of $R^{2}$ on the alkenyl carbon that is proximal to the alkynyl moiety. A catalyst loading of $20 \%$ was insufficient for the complete conversion of $1 \mathrm{c}$, which has a cyclohexyl group as $\mathrm{R}^{1}$ (Table 3 , entry 2). Nonetheless, vinylallene $\mathbf{2}$ ca was obtained in a reasonable yield in the presence of an equivalent amount of the iron catalyst, although its formation was accompanied, to some extent, by reductive product $3 \mathrm{c}$ (Table 3 , entry 3 ). Conversely, it was not possible to achieve a selective 1,5-substitution with the substrates in which $R^{1}$ was $t$ Bu (Table 3 , entry 4 ) or $R^{2}$ was larger than $\mathrm{Bu}$ (Table 3, entries 6-8). Notably, the presence of the $\mathrm{R}^{2}$ group is important for the selectivity of the reaction. The reaction of $\mathbf{1} \mathbf{f}$, in which $R^{2}$ is $H$, yielded a remarkable amount of unidentified by-products, and, therefore, vinylallene $\mathbf{2}$ fa could only be isolated in $68 \%$ purity as determined by ${ }^{1} \mathrm{H}$ NMR analysis using $p$-anisaldehyde as the internal standard. The enyne acetate showed a notably high reactivity when the alkynyl moiety was substituted by a phenyl group [i.e., (E)-1 e], which afforded product 2 ea in high yield (Table 3 , entry 5 ).

It seems that the method was less sensitive towards the nature of the $R^{3}$ group in the allylic position. The acetate of a primary enyne alcohol (i.e., 1 i) or that with a methyl (i.e., 1 j), isopropyl (i.e., 1 k), or phenyl (i.e., 1 I) group in the allylic position underwent the reaction smoothly with $\mathrm{BuMgCl}$ to afford the desired vinylallenes in good to high yields (Table 3, entries 9-12). However, vinylallene 2 la was only recovered in $85 \%$ purity because of its low stability (Table 3, entry 12 ).

Finally the iron-promoted process was also examined for substrate $1 \mathrm{~m}$, which has an endocyclic double bond. In contrast to the acyclic enyne reagents tested herein, $1 \mathrm{~m}$ was completely unreactive and almost entirely recovered at the end of the process (Scheme 3).

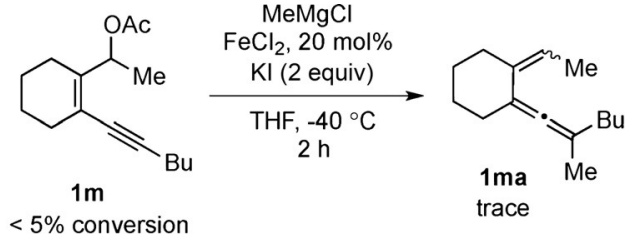

Scheme 3. 1,5-Substitution of $1 \mathrm{~m}$.

In an effort to study the chirality transfer ability of the method, an enantioenriched enyne acetate was subjected to the 1,5-substitution reaction with EtMgBr under the optimized conditions. At the end of the reaction, vinylallene product 2 ah was isolated in $88 \%$ yield, but as a racemate, which illustrates that the reaction cycle proceeds with complete loss of chirality (Scheme 4).

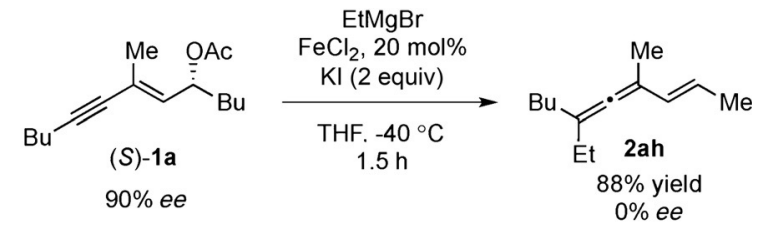

Scheme 4. 1,5-Substitution of enantioenriched enyne acetate.

\section{Iron-Promoted Reaction of Enyne Oxiranes and Grignard Re- agents}

After showing that 2-en-4-yne acetates are perfectly amenable reagents towards 1,5-substitution reactions in the presence iron catalysis to generate vinylallenes, we then extended our studies to enyne oxiranes 4 . A THF solution of $\mathbf{4}$ was added dropwise (15-20 $\mathrm{min}$ ) to a mixture of a Grignard reagent and iron compound at $-50^{\circ} \mathrm{C}$ and further stirred for a period of time. ${ }^{[12]}$ As a result, enyne oxiranes that contain a (Z)-configured alkenyl moiety can typically undergo a clean reaction with primary Grignard reagents to furnish (E)-configured vinylallenes $\mathbf{5}$ that have a hydroxyl group at the allylic carbon (Table 4, entries 1-4). ${ }^{[13]}$ No reduction products were detected in the absence of a salt additive during these studies. Products $\mathbf{5} \mathrm{ab}, \mathbf{5} \mathrm{ah}, \mathbf{5} \mathrm{ac}$, and $\mathbf{5} \mathrm{ad}$, however, were usually obtained in low diasteromeric ratios in terms of relative configurations of the allenyl moiety and allylic carbon with the major diastereomeric forms from the anti-mode displacement. ${ }^{[14]}$ This low diastereoselectivity was the direct result of the low level of chirality transfer from the chiral center of the substrate to the stereogenic axis of the vinylallenes, which is in agreement with the usual behavior of the enyne acetates in this study.

The reactions of the enyne oxiranes were also sensitive to steric effects. The reaction of (Z)-4a with $i \mathrm{PrMgCl}$ led to an intricate mixture of products (Table 4, entry 5), and thus no meaningful recovery of a vinylallene structure was achievable. Only a modest yield of $\mathbf{5}$ ag was obtained with the use of $\mathrm{PhMgCl}$ (Table 4, entry 6). The 1,5-substitution reactions with $\mathrm{BnMgCl}$ and allylMgCl were not feasible either and exclusively led to $S_{N} 2$ products, which were likely produced by an uncata- 
Table 4. 1,5-substitution of the enyne oxirane (Z)-4a with various Grignard reagents. ${ }^{\left[{ }^{[]}\right.}$

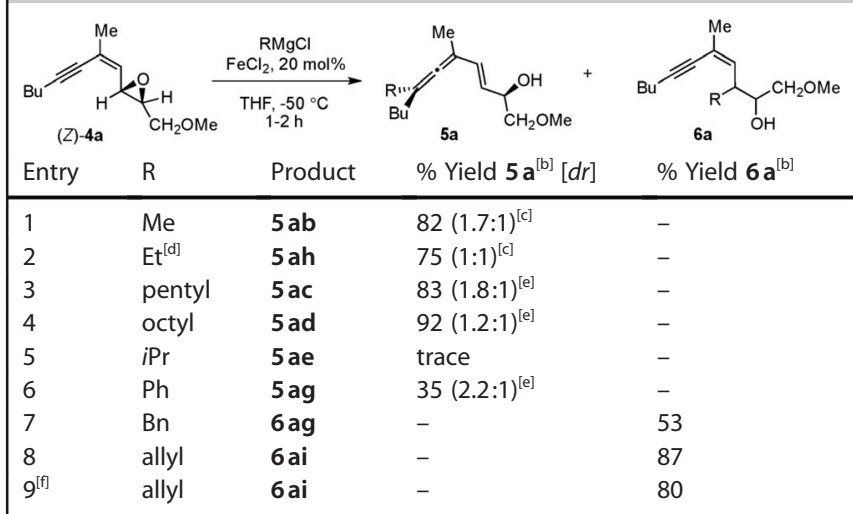

[a] Reagents and conditions: 1 a $(0.1 \mathrm{mmol})$ and $\mathrm{RMgCl}$ (3 equiv) in THF $(3 \mathrm{~mL})$. [b] Yields of isolated products are provided. [c] Diastereomeric ratio (dr) was determined by ${ }^{1} \mathrm{H}$ NMR analysis. [d] Performed with EtMgBr. [e] Determined by HPLC analysis. [f] Performed in the absence of the iron compound.

lyzed pathway as concluded from the result of the catalyst-free control experiment with allylMgBr (Table 4, entries 7-9). The benzyl and allyl iron species, which may have been formed in a transmetalation step, were most likely too stable to be involved in further steps of the reaction cycle.

It seems that the enyne oxiranes that contain an $(E)$-configured alkenyl moiety were not suitable substrates for the method. The reaction of $(E)-\mathbf{4}$ a with EtMgBr did not cleanly proceed but yielded vinylallene $(E)-5$ ah in a low yield $(43 \%)$ because of the formation of unidentified by-products (Scheme 5).

It is important to protect the pendant oxygen functionality of the enyne oxirane substrates for effective regioselectivity. The benzyl- [i.e., (Z)-4 b] and silyl-protected [i.e., (Z)-4c] substrates were employed without a problem (Table 5, entries 1 and 2), but the reaction of related substrate $(Z)-\mathbf{4} d$, in which the hydroxyl group is unprotected, with $\mathrm{MeMgCl}$ in the presence of $20 \mathrm{~mol} \% \mathrm{FeCl}_{2}$ led to a mixture of both the corresponding vinylallene $5 \mathrm{db}$ and $\mathrm{S}_{\mathrm{N}} 2$ product $6 \mathrm{db}$ in yields of 54 and $11 \%$, respectively (Table 5 , entry 3 ). On the other hand, varying the substituent pattern on the oxirane terminus such as the presence of a methyl [i.e., (Z)-4 e], dimethyl [i.e., (Z)-4 f], and 2-methoxypropan-2-yl groups [i.e., (Z)-4 g] or in the absence of any terminal group [i.e., $(Z)-\mathbf{4 h}$ ] had little effect on the product efficacy of the process (Table 5, entries 4-7).

Unlike its enyne acetate counterpart, enyne oxiranes that have terminal alkynyl moieties [i.e., (Z)-4i and (Z)-4j] function

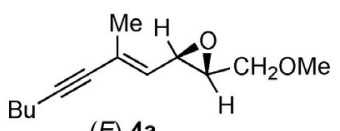

$(E)-4 a$

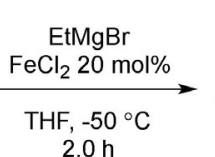

$2.0 \mathrm{~h}$

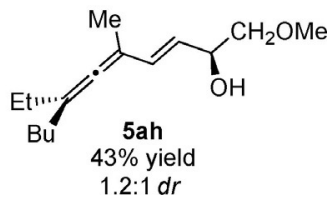

1.2:1 dr
Scheme 5. 1,5-Substitution of $(E)-4$ a with EtMgBr. perfectly in the 1,5-substitution reaction (Table 5, entries 8 and 9). In fact, the best stereoselectivity among all of the substrates in this study resulted from the reaction of (Z)-4i $\mathbf{i}$, which underwent the 1,5-substitution to afford the vinylallene with a synthetically useful $d r$ of 5.7:1. The method also operates well with substrates that contain a methyl or cyclohexyl $\left(R^{1}\right)$ group on the alkynyl carbon (Table 5, entries 10 and 11). Nevertheless, only moderate yields of the corresponding vinylallenes were isolated when $\mathrm{R}^{1}$ corresponds to the bulky tert-butyl or phenyl group, and a relatively high iron content was required in these reactions (Table 5, entries 12 and 13). Moreover, the reaction of 40 , in which $\mathrm{R}^{1}$ is $\mathrm{Me}_{3} \mathrm{Si}$, led to a complex mixture, and there was virtually no formation of the desired vinyl alkene (Table 5, entry 14).

The reaction of the enyne oxiranes was also sensitive to size of substituent $R^{2}$. Although no problems were encountered when $\mathrm{R}^{2}$ was $\mathrm{H}$ or $\mathrm{Bu}$, a moderate yield was obtained with a larger cyclohexyl (Cy) group as $\mathrm{R}^{2}$. In addition, this method could not tolerate the tert-butyl group at all as $R^{2}$ (Table 5, entries 15-18).

Although there is not a clear understanding of the reaction mechanism at the moment, it is likely that the catalytic cycle should involve $\pi$-allyl iron intermediate $\mathbf{A}$, which is generated from 1 or $\mathbf{4}$ by displacement of the leaving group predominantly through the anti mode (Scheme 6). ${ }^{[15]}$ The shift of the iron atom to the distal alkynyl carbon affords $\sigma$-allenyl iron complex $\mathbf{B}$, and the subsequent migration of the $\mathrm{R}^{4}$ group to the allenyl carbon should result in vinylallene $\mathbf{2}$ or $\mathbf{5}$. The loss<smiles>[R]C=CC([R])=C([R])C([R])=CC(C)C</smiles>

Scheme 6. Reaction mechanism for 1,5-substitution.

of stereochemical integrity in the resulting products is proposed to occur during the course of reaction cycle, as a diastereomer of vinylallene $\mathbf{5} \mathbf{n a}$, prepared by another method, retained the original 1:11.5 dr when treated to standard conditions both in the presence and absence of a Grignard reagent. ${ }^{[14]}$ This method is sensitive to the size of the $R^{1}$ and $R^{2}$ groups of the enyne substrates as well as $R^{4}$ of the Grignard reagent, which is well in line with the proposed mechanism. A bulky $R^{2}$ group can hinder the migration of the $\pi$-allyl coordinated iron to the alkynyl moiety. In addition, bulky Grignard reagents would also have difficulty migrating with an $R^{2}$ barrier.

Fürstner and Méndez displayed that iron-catalyzed reactions of propargyl epoxides with Grignard reagents give syn-configurated 2,3-allenols as the major products and suggested that this selectivity is directed through the coordination of a catalyst or Grignard reagent with the epoxide oxygen atom. ${ }^{[6]}$ Such a coordinative pathway is not likely to occur in our case, as this route cannot account for as the ob- 
Table 5. 1,5-Substitution of (Z)-enyne oxiranes with Grignard reagents. ${ }^{[a]}$

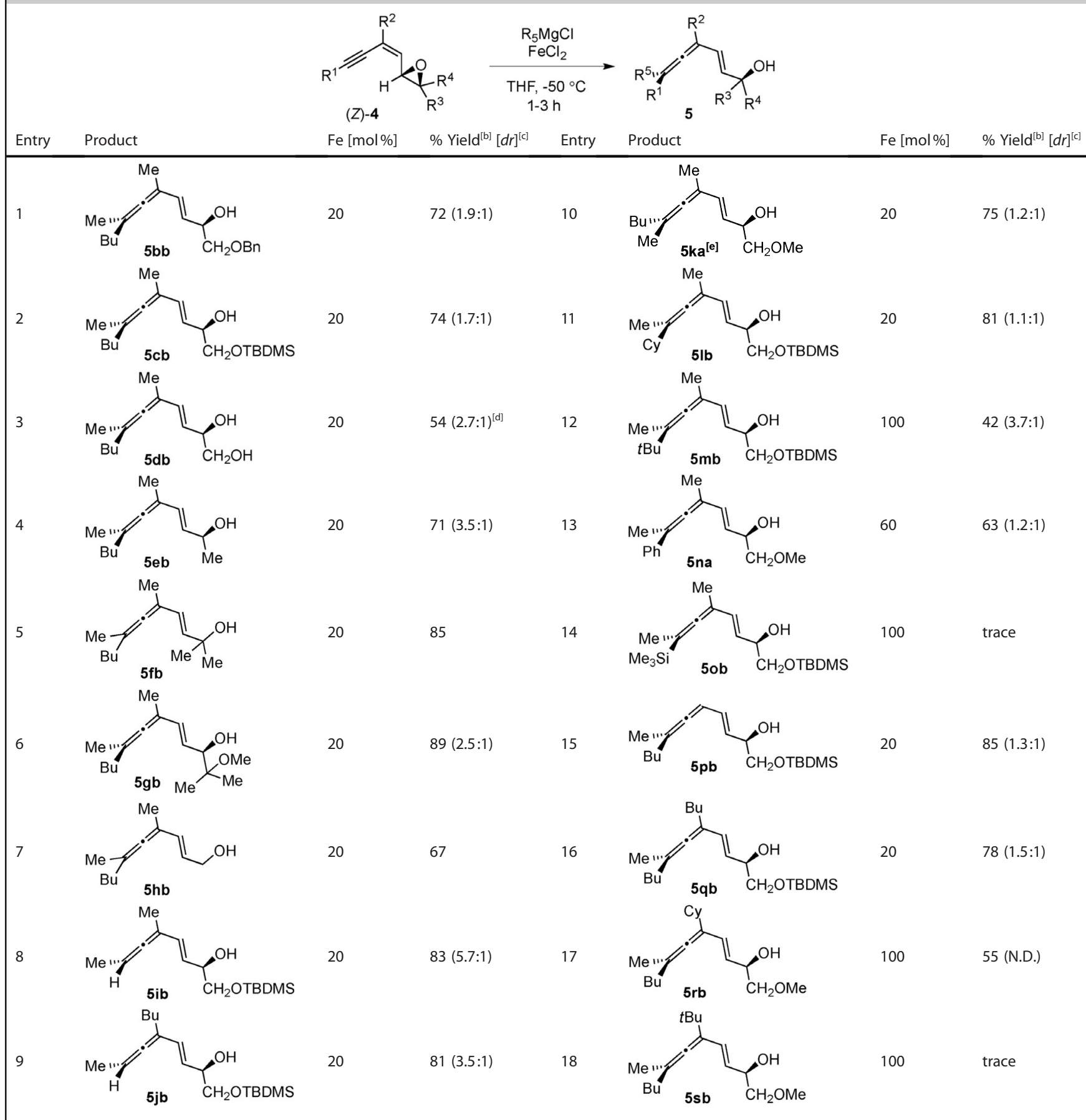

[a] Reagents and conditions: 1 a $(0.1 \mathrm{mmol})$ and $\mathrm{RMgCl}$ (3 equiv) in THF ( $3 \mathrm{~mL})$. Disubstituted epoxide rings were in the $(E)$-isomeric forms. [b] Yields of isolated products are provided. [c] Determined by ${ }^{1} \mathrm{H}$ NMR analysis (N.D. = not determined). [d] Accompanied by $11 \%$ of $6 \mathrm{db}$ formation. [e] Diastereomer of $5 \mathrm{ab}$.

served steric effects of the $\mathrm{R}^{2}$ and $\mathrm{R}^{4}$ groups as well as the anti selectivity.

\section{Conclusions}

Enyne acetates 1 and enyne oxiranes 4 that have different substitution patterns were synthesized and subjected to treatment with Grignard reagents in the presence of $\mathrm{FeCl}_{2}$. The reactions proceeded through 1,5-substitution $\left(\mathrm{S}_{\mathrm{N}} 2^{\prime \prime}\right)$ reactions to exclusively yield $(E)$-configured vinylallenes. The addition of an alkali salt to the reactions of $\mathbf{1}$ suppressed the hydride-involving reductive 1,5-substitution pathway that led to vinylallene byproducts 3 and improved the carbon-carbon coupled vinylallene $\mathbf{2}$ formation. No additive was needed for effective conver- 
sion of enyne oxiranes 4 . The method appears to be sensitive to the steric factors within the substrate and Grignard reagent.

\section{Experimental Section}

General procedures for the 1,5-substitution reactions and characterization data are provided in the Supporting Information.

\section{Acknowledgements}

Financial support from the Scientific and Technological Research Council of Turkey (113Z155) is gratefully acknowledged. We thank Ms. Filiz Kurucaovalı of the Environmental Research Center of Izmir Institute of Technology for HRMS analyses.

\section{Conflict of interest}

The authors declare no conflict of interest.

Keywords: enynes - Grignard reaction - iron · nucleophilic substitution - regioselectivity

[1] a) M. Bertrand, J. Grimaldi, B. Waegell, Chem. Commun. 1968, 1141 1142 ; b) R. Baudouy, F. Delbecq, J. Gore, Tetrahedron 1980, 36, $189-$ 195; c) R. Schneider, H. Siegel, H. Hopf, Liebigs Ann. Chem. 1981, 1812 1825; d) E. A. Deutsch, B. B. Snider, J. Org. Chem. 1982, 47, 2682-2684; e) G. A. Tolstikov, T. Y. Romanova, A. V. Kuchin, J. Organomet. Chem. 1985, 285, $71-82$; f) H. J. Reich, E. K. Eisenhart, W. L. Whipple, M. J. Kelly, J. Am. Chem. Soc. 1988, 110,6432-6442; g) K. K. Wang, Y. W. Andemichael, S. Dhumrongvaraporn, Tetrahedron Lett. 1989, 30, 1311-1314; h) U. Koop, G. Handke, N. Krause, Liebigs Ann. 1996, 1487-1499; i) M. Murakami, M. Ubukata, K. Itami, Y. Ito, Angew. Chem. Int. Ed. 1998, 37, 2248-2250; Angew. Chem. 1998, 110, 2362-2364; j) M. Murakami, K. Itami, Y. Ito, Organometallics 1999, 18, 1326-1336; k) M. Murakami, K. Itami, Y. Ito, J. Am. Chem. Soc. 1999, 121, 4130-4135; I) D. Regás, M. M. Afonso, M. L. Rodríguez, J. A. Palenzuela, J. Org. Chem. 2003, 68, $7845-$ 7852; m) M. Murakami, S. Ashida, T. J. Matsuda, J. Am. Chem. Soc. 2004 126, 10838-10839; n) J. H. Lee, F. D. Toste, Angew. Chem. Int. Ed. 2007 46, 912-914; Angew. Chem. 2007, 119, 930-932; o) H. Funami, H. Kusama, N. Iwasawa, Angew. Chem. Int. Ed. 2007, 46, 909-911; Angew. Chem. 2007, 119, 927-929; p) M. Yang, N. Yokokawa, H. Ohmiya, M. Sawamura, Org. Lett. 2012, 14, 816-819; q) K. M. Wu, M. M. Midland, W. H. Okamura, J. Org. Chem. 1990, 55, 4381-4392; r) S. López, J. Rodríguez, J. G. Rey, A. R. de Lera, J. Am. Chem. Soc. 1996, 118, 1881-1891; s) J. A. Souto, M. Pérez, C. S. López, R. Alvarez, A. Torrado, A. R. de Lera, J. Org. Chem. 2010, 75, 4453-4462; t) C. Spino, C. Thibault, S. Gingras, J. Org. Chem. 1998, 63, 5283-5287.

[2] a) N. Krause, Liebigs Ann. Chem. 1993, 521-525; b) S. L. Schreiber, L. L. Kiessling, J. Am. Chem. Soc. 1988, 110, 631-633; c) R. A. Gibbs, K. Bartels, R. W. K. Lee, W. H. Okamura, J. Am. Chem. Soc. 1989, 111, $3717-$ 3725.

[3] a) J. Goré, J. P. Dulcere, J. Chem. Soc., Chem. Commun. 1972, 866-867; b) J. P. Dulcere, J. Grimaldi, M. Santelli, Tetrahedron Lett. 1981, 22, 31793180.

[4] a) M. Purpura, N. Krause, Eur. J. Org. Chem. 1999, 267-275; b) N. Krause, M. Purpura, Angew. Chem. Int. Ed. 2000, 39, 4355-4356; Angew. Chem. 2000, 112, 4512-4514.
[5] a) G. E. Akpınar, M. Kuş, M. Üçüncü, E. Karakuş, L. Artok, Org. Lett. 2011 13, 748-751; b) M. Üçüncü, E. Karakuş, M. Kuş, G. E. Akpınar, Ö. AksınArtok, N. Krause, S. Karaca, N. Elmacı, L. Artok, J. Org. Chem. 2011, 76, 5959-5971; c) E. Ş. Karagöz, M. Kuş, G. E. Akpınar, L. Artok, J. Org. Chem. 2014, 79, 9222-9230; d) M. Kuş, L. Artok, M. Aygün, J. Org. Chem. 2015 $80,5494-5506$

[6] A. Fürstner, M. Méndez, Angew. Chem. Int. Ed. 2003, 42, 5355-5357; Angew. Chem. 2003, 115, 5513-5515.

[7] T. Hata, S. Iwata, S. Seto, H. Urabe, Adv. Synth. Catal. 2012, 354, 1885 1889.

[8] For other examples of iron-catalyzed substitution and addition processes that involve Grignard reagents, see: a) T. Hata, R. Bannai, M. Otsuki, H. Urabe, Org. Lett. 2010, 12, $1012-1014$; b) T. Hata, T. Nakada, Y. T. Oh, N. Hirone, H. Urabe, Adv. Synth. Catal. 2013, 355, 1736-1740; c) C.-L. Sun, A. Fürstner, Angew. Chem. Int. Ed. 2013, 52, 13071-13075; Angew. Chem. 2013, 125, 13309-13313; d) G. Chai, R. Zeng, C. Fu, S. Ma, Eur. J. Org. Chem. 2013, 148-154; e) X. Zhang, Y. Qiu, C. Fu, S. Ma, Org. Chem. Front. 2014, 1, 247-252; f) D. J. Tindall, H. Krause, A. Fürstner, Adv. Synth. Catal. 2016, 358, 2398-2403.

[9] a) E. C. Ashby, S. A. Noding, J. Org. Chem. 1979, 44, 4371-4377; b) T. Imamoto, N. Takiyama, K. Nakamura, T. Hatajima, Y. Kamiya, J. Am. Chem. Soc. 1989, 111, 4392-4398; c) H. G. Richey, Jr., J. P. DeStephano, J. Org. Chem. 1990, 55, $3281-3286$; d) H. Schumann, M. Glanz, J. Gottfriedsen, S. Dechert, D. Wolff, Pure Appl. Chem. 2001, 73, 279-282; e) A. Krasovskiy, P. Knochel, Angew. Chem. Int. Ed. 2004, 43, 3333-3336; Angew. Chem. 2004, 116, 3396-3399; f) A. Krasovskiy, F. Kopp, P. Knochel, Angew. Chem. Int. Ed. 2006, 45, 497-500; Angew. Chem. 2006, 118, 511 515; g) M. Hatano, O. Ito, S. Suzuki, K. Ishihara, J. Org. Chem. 2010, 75, $5008-5016$.

[10] a) P. A. Bartlett, W. S. Johnson, Tetrahedron Lett. 1970, 11, 4459-4462; b) G. A. Olah, S. C. Narang, B. G. B. Gupta, R. Malhotra, J. Org. Chem. 1979, 44, 1247-1251; c) M. C. D. Giovanni, D. Misiti, C. Villani, G. Zappia, Tetrahedron: Asymmetry 1996, 7, 2277-2286; d) S. Mattsson, M. Dahlström, S. Karlsson, Tetrahedron Lett. 2007, 48, 2497-2499.

[11] The isolated product 2 ad of the reaction with octylMgCl is contaminated with $4 \mathrm{~mol} \%$ of the homocoupling product hexadecane.

[12] Unlike the reactions with 1, those initiated by the addition of Grignard reagents to the mixture of $\mathbf{4}$ and the iron catalyst resulted in less reproducible results.

[13] Copper catalysts were found to be unsuitable for the 1,5-substitution of 4 . The $S_{N} 2$ product 6 invariably resulted as the major product in the presence of copper reagents such as $\mathrm{Cul}, \mathrm{CuBr}, \mathrm{CuCl}$, and $\mathrm{CuCN}$.

[14] Relative configurations of products 5 were determined by comparing NMR spectra with aryl-substituted vinylallene samples with high $d r$ values. These samples were obtained from Pd-catalyzed arylation reactions of $\mathbf{4}$ in a yet to be published study by F. Ziyanak, L. Alkan-Karadeniz, and L. Artok (the manuscript in preparation).

[15] For reported methods that involve $\pi$-allyl iron intermediates, see: a) $M$. Nakamura, K. Matsuo, T. Inoue, E. Nakamura, Org. Lett. 2003, 5, 1373 1375 ; b) A. Fürstner, R. Martin, H. Krause, G. Seidel, R. Goddard, C. W. Lehmann, J. Am. Chem. Soc. 2008, 130, 8773-8787; c) G. S. Silverman, S. Strickland, K. M. Nicholas, Organometallics 1986, 5, 2117-2124; d) B. Åkermark, M. P. T. Sjögren, Adv. Synth. Catal. 2007, 349, $2641-2646$; e) B. Plietker, A. Dieskau, K. M. A. Jatsch, Angew. Chem. Int. Ed. 2008, 47, $198-$ 201; Angew. Chem. 2008, 120, 204-207.

Manuscript received: April 14, 2017

Revised manuscript received: May 22, 2017

Accepted manuscript online: May 27, 2017

Version of record online: July 19, 2017 